\title{
Empirical Tests of Knowledge and Belief Conflict for the Religious Public
}

In Chapters 2 and 3 I showed that the academic religion and science debate presumes systemic knowledge conflict and that science and religion are logically coherent intellectual structures of justificatory belief about nature. If this were the case, conservative Protestants would be opposed to a fact-claim made by scientists (such as humans evolving from other primates) because they hold a different higher-level justificatory belief than scientists do, such as "Facts can be determined through Biblical exegesis." Critically, a conservative Protestant would be inclined to not believe in any scientific claim, since scientific facts were derived using the wrong higher-level belief.

A second position that is not advocated for or described by academics in the religion and science debates, but that is suggested by contemporary studies of American religion, is propositional belief conflict-that some religious people do oppose particular fact-claims of science (like humans evolving from other primates), but not because this fact was generated through a scientific way of knowing. They may just have been taught differently and believe religious authority and not scientific authority in this one instance. For elites, systemic knowledge conflict is plausible and propositional belief conflict is implausible, as elites are encouraged to create systemic knowledge structures. This is likely to be the reverse for the religious public. That is, it is likely that there is no systemic knowledge conflict, but there is possibly some propositional belief conflict. In this Chapter, I put this thesis about the public to the test.

In the previous two chapters I relied upon other scholarship to suggest the plausibility of my interpretation of the relationship between religion and science. This was necessary because data to precisely test my claims does not exist. I would 
argue that this is because the academics who produce such data largely assume the systemic knowledge conflict when they gather data. In this and the next chapter I conduct indirect tests from available data that allow us to infer the existence of the relationships I posit. In the second half of this chapter, I try to explain the patterns I find.

\section{SURVEY TESTS OF KNOWLEDGE CONFLICT}

I ultimately want to make empirical claims about the U.S. public, and the best way to make a generalizable claim about the U.S. population is to use a nationally representative survey. My first survey analyses use the General Social Survey (GSS), a high-quality nationally representative survey paid for by the National Science Foundation that has been fielded since the early 1970s. The basic logic of survey analysis is to see if one type of person (e.g., an evangelical) is more likely than another (e.g., a nonreligious person) to have a particular view, be engaged in a particular practice, or have a particular identity. The raw averages in response to a survey are usually not very relevant, because the percentage agreeing is so dependent upon question wording. For example, the percent of the population who are Young Earth Creationists is very dependent on how that question is asked. The more analytic tradition is to compare two groups of people who have been asked the same question. That is, we could show that 60 percent of evangelicals were identified as Young Earth Creationists using our question, but only 35 percent of the nonreligious. This is the standard for scholarly analysis of surveys.

The power of being able to make nationally representative claims with a survey comes at a steep price-the thinness of how concepts are measured. For example, while scholars have written one-hundred-and-fifty-thousand-word books about what "creationism" means, a survey might be limited to ten words to describe the phenomenon. Surveys are ideally used in conjunction with more rich data, and that is why I have been building my case using the more expansive, yet typically nonrepresentative data from others' research.

The first question I examine using survey data is the most basic: do religious people disagree with all scientific claims about nature? If so, then the strongest version of the systemic knowledge conflict perspective is correct. The first step is then to measure the religion of the respondent because, as we saw in the previous chapter, different religions have different relationships to science.

With the survey I can determine whether a respondent is a frequent church attender with an identity as a literalist conservative Protestant, nonliteralist conservative Protestant, conservative Catholic, nonconservative Catholic, Black Protestant, or Mainline Protestant. The literalist/nonliteralist distinction is meant to distinguish between those who are most likely to be taught religious fact-claims that conflict with scientific fact-claims, and who would, if the 
systemic knowledge conflict is truly operative, be most likely to be taught an alternative epistemology.

The attendance threshold for each of these religious identities is designed to identify respondents who actually participate in the discourse of the religion, not those who simply have an identity from their youth. For statistical reasons, groups of less than 4 or 5 percent of the entire sample cannot really be separately analyzed. Therefore, all of the religious minorities who do not fit into one of the categories above are put into one group that is not separately analyzed, due to its heterogeneity, but necessary to include in statistical calculations to make the correct comparisons.

But, compared to whom would committed literalist conservative Protestants be more likely to be opposed to scientific claims? Social science research either explicitly or implicitly makes comparisons, so what we need is a comparison group. For example, if the question is whether conservative Protestants avoid exposure to science to avoid knowledge conflict, we have to account for the fact that most Americans avoid exposure to science. The test, in this particular example, is whether a religious group is avoiding science more than those who are not exposed to the religious teaching.

The comparison should be to the nonreligious, because the debate is implicitly framed as the religious having a different view than those who are not religious, who are then, implicitly, scientific. This is not about belief in God per se, as belief in God is compatible with all but the most extreme versions of metaphysical naturalism held by scientific atheists. And, most Americans believe in God, so atheists are not the proper comparison group. Rather, the nonreligious comparison group should be people who are not exposed to religious teachings (even if they residually believe in God). In my first survey analysis, this nonreligious group is best represented by the 54 percent of the public who do not participate in religion. In that analysis, survey non-participation means claiming to attend services "several times a year" or less. ${ }^{1}$

Therefore, the systemic knowledge conflict thesis would predict that: Compared to the non-participants in religion, participating literalist conservative Protestants will tend to avoid being exposed to all science, presumably because their tradition has an alterative epistemology of biblical exegesis for all scientific claims. If there is propositional belief conflict, then we would see members of a religious tradition participate in science as much as anyone else, but not believe in the few claims that conflict with a religiously derived fact-claim (like human evolution).

To measure belief in religiously derived facts about the world, I create a category I call "contested facts," where science and a religion make contrary claims. Respondents were asked a series of fact questions and evaluated as to the extent they knew the scientifically correct answers. These included two "facts" that are actually contested by many conservative Protestants: whether the universe began 
with a huge explosion; and whether human beings, as we know them today, developed from earlier species of animals. The answers to these two questions were combined into a numeric scale that ranged from getting both "wrong" to getting both "right." Or, in the more neutral language I am trying to use, the scale measures belief in the conservative Protestant versions of facts on one end and scientific versions on the other.

I have a number of ways to measure a respondent's exposure to science. First, exposure is indicated by knowledge of uncontested scientific facts, which are those for which there is no known counter-claim in Christianity, and such knowledge would come from engagement with science. Responses to nine uncontested scientific fact questions were added together to form an overall measure of the extent to which the respondent knows established scientific facts. These fact questions included whether: 1) the center of the Earth is very hot; 2) all radioactivity is manmade; 3) the father's gene decides whether the baby is a boy or a girl; 4) lasers work by focusing sound waves; 5) electrons are smaller than atoms; 6 ) antibiotics kill viruses as well as bacteria; 7) the continents on which we live have been moving their locations for millions of years and will continue to move in the future; ${ }^{2} 8$ ) the Earth goes around the Sun; and 9) how long it takes for the Earth to go around the sun. ${ }^{3}$

The survey also asked a number of questions about the scientific method, such as understanding experimental design and odds. These were combined into an overall measure of the extent to which the respondent understands the methods of science. Similarly, if a respondent is avoiding science because it violates their religiously-derived knowledge, they will not obtain scientific knowledge, and will claim less scientific knowledge. The survey also asked how informed the respondent was about "science and technology", "global warming," and "the North and South poles." These questions were combined to create an overall measure of claimed scientific knowledge.

Not pursuing scientific knowledge is also measured by how many college-level science classes the respondent has taken, and whether they hold an undergraduate degree in a natural science or engineering. ${ }^{4} \mathrm{I}$ also measure whether the respondent is a full-time worker who has an occupation that requires knowledge of science. ${ }^{5}$ These are all measures of acceptance of scientific claims, and with these measures we can see if people in religious traditions that have conflicting propositional belief claims (e.g., conservative Protestantism) are actually in systemic knowledge conflict by rejecting the rest of science.

I use types of regression analysis to determine if there is a relationship between participation in particular religions and knowledge of and exposure to science. I also control for demographic identities that can co-vary with religion and science. These controls are important because, for example, if I see a relationship between religious participation and less exposure to science, it could actually be 
that what I am actually seeing is the hidden effect of gender. Women are more religious, and perhaps they have less exposure to science, so what seems to be a relationship between religion and science may actually be about gender. To avoid these problems, I use statistical controls for variables that may vary with religion and may also predict pursuit of scientific knowledge, including education, age, family income, gender, African American ethnicity, Hispanic ethnicity, southern residence, and rural residence.

With the setup in place, we are now ready to run some tests. The first is of propositional belief conflict-are there religious groups where the members do not agree with some of the claims of scientists? For this I see if members of religious groups "know" fewer of the contested scientific facts about the origins of the universe and of humans-after statistically controlling for all of the other reasons they might not know the scientifically correct answer, such as their level of education. We can then assume that they get these questions "wrong," because they disagree with the scientists, not because they do not know what scientists' claim.

To see the formal statistical results, see either the technical published papers or the tables in the online appendix, both of which are referenced in the endnotes. Since regression results are not intuitively understandable, to understand the magnitude of these differences, Table 1 reports the predicted probabilities for hypothetical ideal-type respondents to the survey. ${ }^{6}$ For example, the first entry in the first line lists the average number of religiously contested scientific "facts" that a literalist, high-attending conservative Protestant knows, after controlling for reasons they would not know these facts. This sort of "average" hypothetical respondent is also set to be as close to an average respondent in the survey as is possible, in that she is a Caucasian woman who lives outside the south in a nonrural area, with the average age, income, and education of the respondents included in that particular analysis. In each line, the critical comparison is between a religious group and the nonreligious category in the final column.

For example, the average nonreligious respondent knows on average nearly one of the two contested facts (.97), which does suggest limited knowledge of science in the public in general. But, a literalist conservative Protestant with the same level of education, income and age, and the same race, gender and region of residence, only knows the scientific version of .28 facts. That is, literalist conservative Protestants are much less likely to know these facts. (At least one " " in the table means that the difference between that number and the one in the final column is not simply due to chance-technically called statistical significance. If there is no " $¥$ " it means that the difference is so small it could be the result of chance in the selection of the survey population.)

We find nonliteralists, mainline Protestants, and black Protestants to be somewhat more likely, followed by Catholics. Again, since I have controlled for being in a position to know what science claims about these facts, I interpret not knowing as 


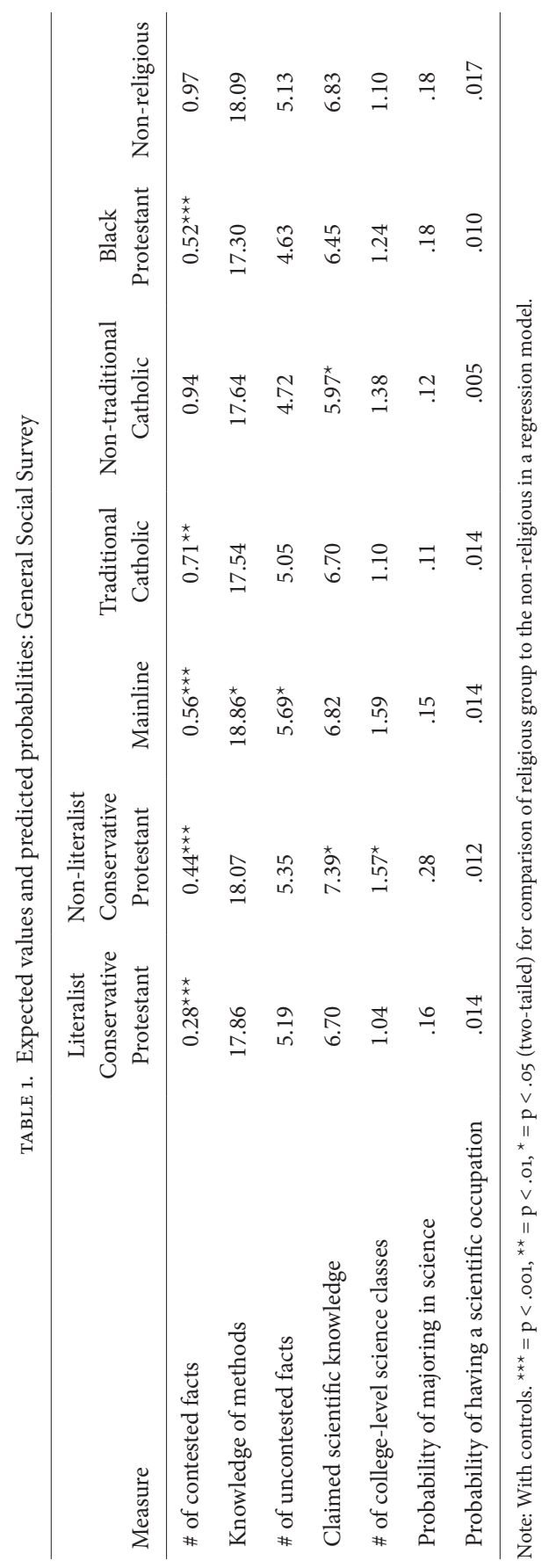


disagreement. Therefore, every religious group but the nonconservative Catholics disagree with the scientific "facts" compared to the nonreligious. That is, members of most Christian groups, liberal and conservative, are in propositional belief conflict with science over these few contested facts. This is contrary to what we would expect from the official teachings in the more liberal groups, and I will offer explanations for this discrepancy later in this chapter.

I am primarily interested in the assumption of systemic knowledge conflict, where believing a religious fact-claim about evolution, for example, would lead to not believing other scientific fact claims for which there is no conflicting religious version, like global warming. If there is systemic knowledge conflict, then members of those religious groups that have propositional conflict with science-and conservative Protestants in particular-should avoid exposure to all of science.

The rest of Table 1 shows that there is no religious group whose members are more likely to avoid noncontested parts of science compared to the nonreligious. The second line in Table 1 shows that the only difference between participants in religious traditions and the nonreligious in knowledge of scientific methods is that mainline Protestants know slightly more science than do nonparticipants in religion. Again, this means that, as I control for the level of education of the respondent, literalist conservative Protestants with college educations-and thus with equal chance of exposure to science-are equally likely to know the scientific method as the nonreligious with college educations.

The systemic knowledge conflict thesis would also predict that conservative Protestants would hear religious fact claims that conflict with scientific claims, conclude that the scientific way of knowing is opposed to the Biblical way of knowing, and therefore avoid science knowledge and thus know fewer science facts. However, Line 3 in Table 1 shows that there is no religious group that knows less, and that mainline Protestants know more established scientific facts than those who are not religiously active.

Similarly, the fourth row is for the measure of claiming to know more scientific knowledge. The scale of this measure is not intuitive, but it ranges from zero to twelve, with higher numbers meaning more knowledge. This analysis shows that the only difference with the nonreligious is that nonliteralist conservative Protestants claim to know more scientific knowledge than do the nonreligious. (Nontraditionalist Catholics claim less knowledge than do the nonreligious, which is an outlier finding in these analyses.)

If conservative Protestants are avoiding all science, they should have taken fewer college-level science classes, be less likely to have majored in science and engineering, and be less likely to have a scientific occupation. The fifth, sixth, and seventh lines show that the only difference between any of the religious groups and the nonparticipants in religion is that nonliteralist conservative Protestants have taken more science classes. The final line in Table 1 shows that there is no religious 
group that is more or less likely to have a scientific occupation than are the nonreligious once we control for factors like education, gender, and age. Overall, this analysis shows that systemic knowledge conflict does not exist for the religious public, including for conservative Protestants.

So far I have shown that there is no religious tradition whose members are in systemic knowledge conflict with science. Despite believing in some nonscientific claims, they are equally likely as the nonreligious to participate in the rest of science. I generally find it useful to compare members of social institutions like religious traditions because we can at least imagine the communication processes like training systems, educational materials, communication channels, and statements of belief that lead to these particular views. But, another tradition in sociology would focus on an individual's beliefs separate from institutions. In this sociological tradition, the test of the systemic knowledge conflict thesis would be whether the individuals who are in propositional belief conflict with science (by not believing the scientific version of the contested fact claims) are those who are in systemic knowledge conflict, and thus avoid any science. I conducted additional analyses using these different assumptions and reached the same conclusions as the previous analysis. ${ }^{7}$

\section{A Socially Urgent Issue: Scientific Claims about Global Warming}

In the first few pages of this book I gave examples of how participants in the public sphere who want to combat global warming were making the false assumption that religious conservatives would deny scientific claims about anthropogenic climate change because they do not believe science in general. This, I claimed, was distorting public debate. This is then a great issue to specifically examine for systemic knowledge conflict.

This is also a good test of systemic knowledge conflict for conservative Protestants because there is not an explicit propositional belief claim in this tradition that contradicts scientific statements about global warming. The Bible does not depict God as saying, "And in later years I will cause global warming." Rather, the few conservative Protestants in the public sphere who contradict scientific claims about global warming using religion appeal to somewhat more abstract higher-level theological beliefs midway up the pyramid about how nature works, such as "God is in control."

Opposition to climate change research is being promoted by ideological conservatives and Republican party activists. ${ }^{8}$ Moreover, a study has recently shown that ideological conservatives are less trusting in science, and conservative Protestants are more likely to be both Republicans and political conservatives, both of which are associated with skepticism about climate change. ${ }^{9}$ Therefore, it is important to determine whether it is religious belief itself, or the political orientation of the 
majority of evangelicals that is associated with not believing scientists' fact-claims about global warming, by controlling for these political measures.

A question in the survey I used above asked: "The first issue is global warming. Global warming means a trend toward warmer temperatures throughout the world, with more extreme weather in many places and changes in food production that could affect our way of life. Some people believe that the burning of gasoline and other fossil fuels causes global warming. Others say that global warming has purely natural causes. ... How well do the following groups understand the causes of global warming? Environmental Scientists." Respondents who believe in the scientific consensus in knowledge about global warming, that global warming is caused by humans, will think scientists understand the causes of global warming. I use the same religion and demographic measures as in previous analyses, and as before, start with comparing members of different religious traditions, followed by comparing those who are in propositional belief conflict with science with those who are not. ${ }^{10}$

The first line of Table 2 shows the predicted probability of a member of each of the religious groups thinking that scientists understand global warming "well" or "very well" without control variables. The probability that a nonreligious respondent will say scientists understand it well or very well is .68, but the probability of a literalist conservative Protestants saying the same is only .55. (A probability of 1.0 means it is a certainty.) This is a small but statistically significant difference. No other religious tradition is different in this view from the nonreligious. That is, analyzing the simple bivariate relationship between religious tradition and believing scientists' fact-claims about global warming shows that literalist conservative Protestants are less likely to believe scientific facts compared to the nonreligious.

However, is this opposition due to the respondent's religion or due to characteristics that people in this religious tradition also tend to have, like political conservatism? In the second line of the table I account for the influence of political ideology and political party identification, and the relationship between literalist conservative Protestantism and believing scientific fact-claims about global warming disappears. With these controls in place, the probability of a literalist conservative Protestant thinking that scientists understand global warming well or very well is .73 , while the probability for the non-religious is $.74 .{ }^{11}$ This small difference is not statistically significant. Therefore, the conservative Protestant effect in the earlier model is not the result of religious belief, but the result of conservative Protestants being more enmeshed in politically conservative and Republican party discourse.

As before, I re-ran this test by not focusing on religious groups, but on individuals who are or are not in propositional belief conflict with science. That is, are the individuals who do not believe science about human origins the same people who do not believe scientists about global warming? This analysis (not shown) reveals 


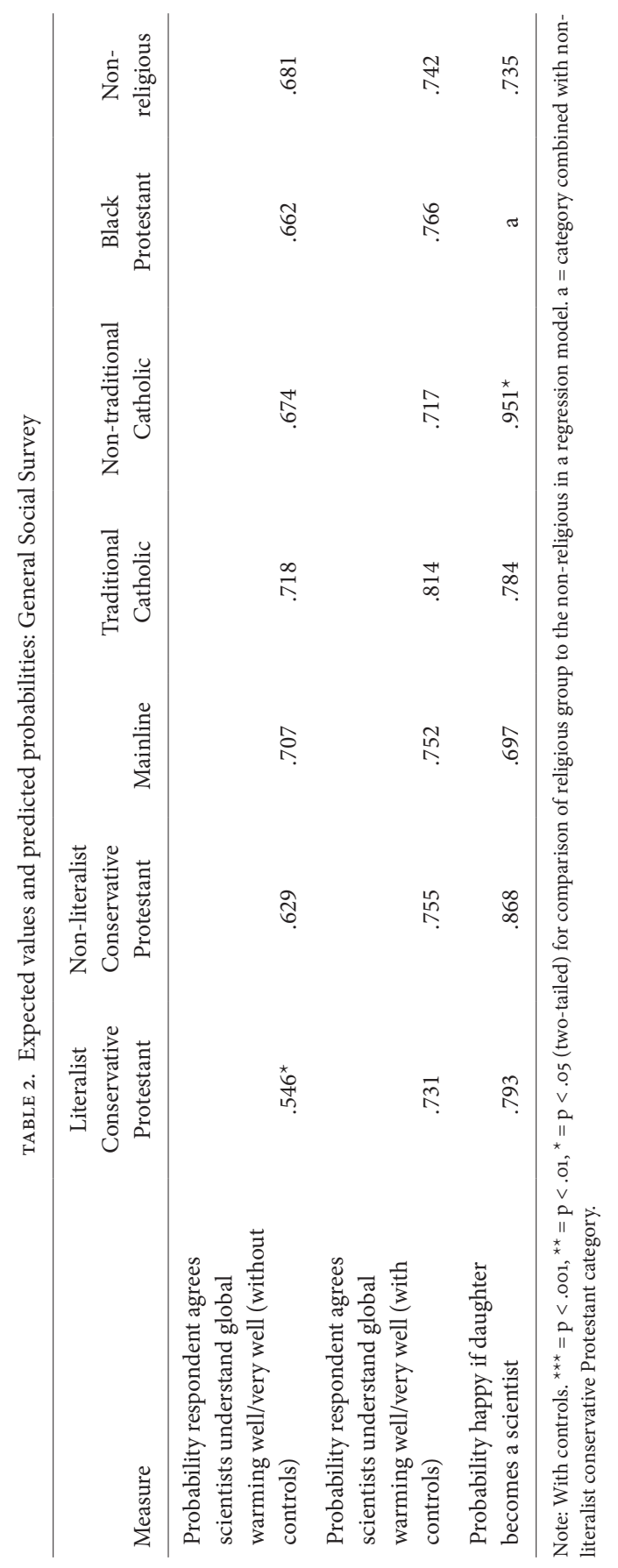


that they are not-believing those religious "facts" is not associated with believing scientists one way or the other about global warming. ${ }^{12}$

This concrete case of scientific claims about global warming reinforces the conclusion that there is no systemic knowledge conflict between any religious group and science. If there were, conservative Protestants would not be willing to accept any scientific claim based upon scientific ways of knowing and would instead appeal to high-level religious ideas to make fact claims about nature. People who do not believe in evolution or the Big Bang would do the same. That not believing scientists on global warming is largely an effect of political ideology — which itself may be a proxy for embeddedness in particular information flows like Fox Newssuggests what the motivations of elite conservative Protestant opponents of global warming science may actually be. ${ }^{13}$

\section{Do You Want Your Child to Be a Scientist?}

When social scientists want to cut to the quick of a respondent's social aversions, they ask what they would want for their children. For example, to measure bias against members of a religion, social scientists often ask respondents if they approve of their children marrying a person from that religion. ${ }^{14}$ In 2012, the GSS asked about wanting your child to be a scientist, and if conservative Protestants were in systemic knowledge conflict with science, they would presumably not want their children to be scientists. However, it is also the case that if they were in total moral conflict with science, they would not want their children to be scientists either. Therefore, the survey question does not allow us to distinguish between knowledge and moral conflict, but allows us to rule out both extreme situations-that conservative Protestants are opposed to all science because of knowledge or moral reasons. Put differently, do conservative Protestants think you can be a "good" scientist?

The question asked "If you had a daughter, how would you feel if she wanted to be a scientist-would you feel happy, unhappy, or would you not care one way or the other?" The raw responses tell us most of what we need to know about conflict over science in the U.S. Of the 517 people who were asked the question, only four selected "unhappy," while five did not know or did not answer. That is, seven-tenths of 1 percent of Americans object to their daughter being a scientist. They asked another question that began "If you had a son ..." One fewer respondent objected to the son being a scientist, for a grand total of three. Essentially nobody is utterly opposed to their child becoming a scientist, so actual opposition will not be found among any religious group. While scientists may be seen as Dr. Frankensteins in waiting, people believe there are either parts of science or individuals in science who are good.

We can look for a milder effect we could call unease at the prospect of their child becoming a scientist by comparing those who said they would be "happy" their 
daughter became a scientist to those who said they would "not care." We should be cautious that this may be measuring a propensity of some religious groups to be less concerned with the occupational choices of their children than a concern about the occupation of science in particular. That said, I analyzed the question about the hypothetical daughter using the same statistical model as above. ${ }^{15}$

The final line in Table 2 shows that the probability that a nonreligious respondent will say they are happy if their daughter becomes a scientist, compared to not caring, is .735. The probability for a literalist conservative Protestant is .793-actually a little higher than the nonreligious, but not a statistically significant difference. ${ }^{16}$ The only statistically significant difference is that nontraditional Catholics are more likely to be happy if their daughter becomes a scientist than would be the non-religious. Therefore, conservative Protestants are not opposed to science writ large on the grounds of either knowledge or morality, but think there are at least parts of science, or individuals in science, that are consistent with conservative Protestant beliefs and values.

In contrast with the academic science and religion debate, for the public it does not appear that there are any systemic knowledge conflicts between religion and science, including with members of the conservative Protestant tradition. What we appear to be left with is what I am calling propositional conflict-conservative Protestants just believe religious versions of facts of the world that they have been taught, and these seem to be unrelated to any other aspects of science.

\section{TOWARD AN EXPLANATION OF WIDESPREAD PROPOSITIONAL BELIEF CONFLICT}

The systemic knowledge conflict perspective provided an easy answer to any conflict between religion and science-the conflict was over entire ways of knowing about the natural world. Now that it has been demonstrated that the systemic knowledge perspective is unlikely, we are adrift without an explanation for the remaining propositional belief conflict that we do see. I see this as opening up a new family of empirical examinations of religion and belief about the natural world that is not constrained by old stereotypes. In this final section I speculate about what conflict about beliefs about the natural world could be about if it is not about systemic knowledge. I look forward to the future scholarship in this area.

\section{Explaining Catholic and Mainline Protestant Propositional Belief Conflict}

While Catholic and mainline Protestants are much less likely to believe conservative Protestant religious claims about human origins than do conservative Protestants, they do believe these claims more than the nonreligious do, and more 
than their leaders or the established theology in their traditions would. This is a bit mysterious. For the mainline Protestants, one explanation is that the mainline laity are much more conservative than their clergy (and the evangelical laity much more liberal than their clergy). Another possible explanation is that it is difficult to tell the difference between a mainline Protestant and an evangelical in a survey, and the highest attending mainline Protestants (who I focus upon) are the most like evangelicals. So, my results could simply be a measurement issue. I also suspect, but cannot prove, that while a mainline Protestant may believe in the Big Bang and human origins as depicted by scientists, they also want to give a response not available in the survey, such as "There is more to it than that." Their view may actually be that the Big Bang occurred, but was caused by God, and not seeing the fullness of what they want to express, they select "No." ${ }^{17}$

The finding for conservative Catholics is similarly surprising. These are the Catholics who should be more attentive to Church teaching, and their answers to these survey questions makes them "bad" Catholics, in that they are contradicting Church teaching. It is possible that while the liberal Catholics just believe what scientists say, in their survey responses the conservative Catholics want to make what they think of as the conservative religious statement. Due to the prominence of the conservative Protestant claims in the public sphere, and being unaware of actual Catholic teaching on this subject, they think that the conservative Protestant belief is the proper "religious" or "Christian" response. Again, it is also possible that they select the nonscientific response about human origins, as if to say "There is more to it than that." Future research with instruments that properly distinguish between the possible types of conflict will hopefully help explain why mainline Protestants and Catholics are in this propositional belief conflict with science.

\section{Conservative Protestants Are Using $19^{\text {th }}$ Century Baconian Science}

For conservative Protestants the question is why they disagree with scientists about these particular fact claims, given that they mostly agree with scientists. One possible explanation is that conservative Protestants are locked into a mid-nineteenth-century version of science that was inspired by Bacon. Returning to my pyramid metaphor, a nineteenth-century Baconian science pyramid of knowledge claims would look very similar to a contemporary science pyramid at the bottom. The two would reach the same conclusions about the majority of fact claims. But, the pyramids would be different starting halfway up, because the principles by which the lower-level knowledge is generated would ultimately be different. Midway up the nineteenth-century version would be the principle that fact claims need to be observable, and that you cannot generate a fact claim via abstractions. Since the Big Bang and human evolution are abstractions that cannot be observed, they are not properly scientific questions, but are religious questions. 
But, observable scientific facts, like a warming earth, would be scientific, and thus scientists' claims should be believed. This would distinguish the scientific claims that are and are not believed.

There is some evidence that at least the elites in contemporary conservative Protestantism are still Baconian, and therefore a scientific claim is only believed if it can be demonstrated through your own senses. This contemporary Baconianism is most evident in debates between what we might call elite fundamentalist literalists and elite fundamentalist superliteralists. The latter are the tiny group of geocentrists who reject modern astronomy to say that since the Bible says that the sun moves around the earth, the sun moves around the earth. Geocentrists are reviled as extremists by the group most people think of as the poster child for epistemological extremism - the creationists who want to defend the young earth and literal Genesis accounts of creation. But, what is useful for my purposes is that the creationists have had to account to the geocentrists why they believe in science in some instances but not others, thus revealing their principles of selecting one scientific claim over another.

In the words of one creationist: "Many evolutionists claim that disbelief in evolution is like disbelief that the earth goes round the sun. The obvious flaw is that the latter is repeatable and observable while the former is not." This means that "the historical sciences, including evolution, are less legitimate than the experimental sciences because they purport to explain unwitnessed and unrepeatable events." Other nongeocentrist creationists state that the geocentrists fail "to take into account a distinction between observations and the conclusions based on observations." As two scholars of creationism note, creationists have long stressed the distinction between “origins science', in which the primary authority is given to Scripture, in contrast to 'operation science,' in which the assured results of current observations and experiments are allowed to influence the interpretation of Scripture." ${ }^{18}$

Elites attempt to teach this Baconian approach to knowledge to fundamentalist Protestant children. The textbook Of Pandas and People: The Central Question of Biological Origins is most famous for teaching an intelligent design perspective on human origins, which has led to the book being a centerpiece in ID court cases. Less remarked upon is the fact that the book also has a "note to teachers" in the back which outlines a proper stance toward developing knowledge about nature. The authors of this section of the textbook want to explain the "scientific method," and make a distinction between the "inductive sciences" - certainly a Baconian term-and the "historical sciences." 19 The "inductive" are also "nomological," which means "relating to or denoting certain principles, such as laws of nature, that are neither logically necessary nor theoretically explicable, but are simply taken as true." 20 "Simply taken as true" is the nineteenth-century Baconian and Scottish Common Sense Realist idea of the transparent truth of observed facts. 
The inductive sciences concern "how the natural world generally operates"-it does not ask how it came to be this way.

On the other hand, "the historical sciences seek to understand how things came to be." In this historical science, "the goal is not to find new laws or regularities but to reconstruct past conditions and events." Critically, "postulating intelligent intervention is completely inappropriate in the inductive sciences, the same is not true in the historical sciences." In the inductive sciences, "the whole point is to discover how the natural world normally operates on its own," no matter how it was created in the first place. ${ }^{21}$ That is, for how the world currently works, fundamentalist kids should use mainstream science. But, as for how things came to be, that is not observable and would be speculation.

All of the theories in the historical sciences pertain to "the unobservable past," including the Big Bang and Darwinism, which postulate "unobservable objects and events." This is straight Baconianism-the observable is science, the unobservable is not science. ${ }^{22}$ The message here is clear-being a good conservative Protestant scientist means using a justificatory science that is ultimately based upon direct observation.

So, this Baconian approach to knowledge continues among the contemporary conservative Protestant elite, who try to teach it to their members. I doubt many ordinary members learn it, as scientific epistemology is not a common sermon topic, and only a small percentage of conservative Protestant children would attend schools that use books like Of Pandas and People. I suspect these kids remember as much of high school science as do secular high school students, which is not much.

For the average conservative Protestant, I think it is more plausible that Baconianism has survived since the nineteenth century by incubating in conservative Protestant biblical hermeneutics, which are definitely learned by the ordinary members. Discussion of how to read the Bible is indisputably a central part of being a conservative Protestant. As described in Chapter 5, a Baconian approach to nature supported a Baconian approach to the Bible, which is that its meaning is on the surface, open to examination like a set of collected plants, with no high theory required to interpret it. Contemporary conservative Protestants are taught that true knowledge of the Bible is uncomplicated, transparent, and available via a common sense reading, so they may think that other knowledge-like knowledge of nature-is similarly uncomplicated, transparent, and available via common sense.

If they continually learn this approach to truth in general, then conservative Protestants will believe scientific claims that can be immediately observed (such as the average temperature of the Earth) and not claims based on "theories" like climate models and "speculations" about prehuman primates who roamed millions of years ago. Even if conservative Protestants never teach their children how 
to interpret nature through science, they may be teaching a general approach to truth claims through biblical hermeneutics.

\section{Defending Literalist Theological Claims ... from Liberal Protestantism}

Another possible explanation for conservative Protestant propositional belief conflict with science over human origins will be obvious to those who know American religious history, once I describe this history using my terminology. If you ask conservative Protestants about human origins, you will often hear the claim that they are defending the truth of the literally read Bible. They would say that if Genesis is not literally true, then the Resurrection is not literally true and the virgin birth is not literally true and so on. A recent ethnography of evangelical high schools confirms that opposition to evolution is primarily about defending the Bible. ${ }^{23}$

Therefore, belief in the conservative Protestant version of human origins is only incidentally a scientific conflict-what they are actually defending is a list of literalist theological claims about the Bible. But, no scientist cares about the Resurrection, the virgin birth, or most of the literalist claims being defended against the liberals. Belief in the conservative Protestant account of human origins is then not a conflict with science per se, but is rather a battle with their archenemies the liberal Protestants, using scientific claims as a weapon. It is liberal Protestants who also care about claims like the Resurrection and the virgin birth, and the proper nightmare for any good fundamentalist is their child becoming a liberal Protestant. It was of course this conflict between fundamentalists and liberals - not fundamentalists and scientists - that shaped American religious history and these religions' approach to knowledge.

So, in this explanation, the reason there is not systemic conflict, but there is propositional belief conflict about human origins, is that they are not really concerned with whether these are knowledge claims about the natural world at all. Rather, they are concerned with defending other sets of nondemonstrable theological belief claims. Therefore, it is possible that conservative Protestants do not think of a six-thousand-year-old Earth or a literal Adam and Eve as scientific claims. They are instead but a few of the many theological statements that must be held to be literally true in order to defend the Bible from liberal Protestantism and secularism (often thought to be the same thing).

\section{Status Politics or Identity Formation for Conservative Protestants}

A fairly old social science tradition holds that "status politics" are political movements concerned with the status of a particular group in society, not necessarily an attempt to gain anything concrete. Some groups are losing prestige in society, and they promote their values as a way of demonstrating that they are still important. ${ }^{24}$ 
In a classic study of American temperance movements, Joseph Gusfield demonstrated that middle-class, small-town Protestants felt their status was declining compared to urban Catholic immigrants, and used temperance to demonstrate the importance of their values. Gusfield demonstrated that it was a symbolic politics because temperance advocates were not very interested in actually stopping people from drinking alcohol, just in establishing a constitutional amendment as a symbol. ${ }^{25}$

We could construct a status politics explanation of why conservative Protestants have not given up on their nonscientific beliefs about human origins, while the liberal Protestants have. It is central to conservative Protestant identity to see themselves as embattled group, whether this is true or not. ${ }^{26}$ It is then not so much that they want to show that Darwin was factually wrong so much as the want to show the importance of the creationist idea that has become symbolic of their religious group. If they can get the public schools to give equal time to creationism, they establish that their religious group still has status in society. Adopting this symbol does not require accepting any larger knowledge structure, because all that is needed is a symbol that has come to represent the group. ${ }^{27}$ This identity explanation is consistent with the survey findings above that show that belief in creationism is not connected to any other aspect of science.

When interviewing conservative Protestants about anything, it is common to be given what are essentially identity-based reasons for beliefs rather than reasons based upon higher-level beliefs. For example, when interviewing conservative Protestants about reproductive genetic technologies, I was often told by respondents that they are opposed to abortion "because I am Christian" and not because "human life begins at conception" or any other higher-level principle.

In the aforementioned ethnography of evangelical high schools, Jeffrey Guhin reaches a similar conclusion about evolution, seeing rejection of evolution as a defense of biblical literalism, which is itself a form of identity boundary-drawing. For evangelicals, the "symbolic boundary" with the secular United States is necessary to differentiate themselves. These boundaries are important for convincing people to be a member of any group, in particular those in which membership comes at a social cost. ${ }^{28}$ If this insight is generalizable beyond Guhin's particular cases, it would suggest that not only would a religious fact-claim not need to be connected to any broader system of knowledge, but that a religious fact-claim that conflicts with a scientific claim is actually more useful for demarcating the border of the group, because science can stand in for secular society.

\section{Moral Opposition to Science by Conservative Protestants}

It is difficult to test these possible reasons as data are not available. However, I think that the final possibility is the most plausible, which is that conservative 
Protestants select religious facts to disagree with scientific facts that have the strongest moral ramifications. That is, not only does moral conflict exist independent of any knowledge concerns, many religious people want to say that evolution is morally incorrect. They then do the next best thing in the context of a survey question-they say it is not true.

I would argue that this is what is occurring with the entire Intelligent Design movement. They seem to be primarily motivated by a concern that Darwinism is teaching that morality is random. They then want to overthrow Darwinism by showing that human evolution was at the hand of a designer. What appears to be about knowledge is actually driven by morality - an explanation I begin to address in the next chapter.

\section{CONCLUSION}

In this chapter I looked for systemic knowledge conflict. This would matter for the lives of citizens, as disbelief in human origins would lead one to not believe chemistry, physics, or any other field requiring the scientific method, and would result in disengagement from society. I did not find it. There does not seem to be any religious group, including conservative Protestantism, that takes the actual action of conflict of avoiding science writ large by not taking science classes, learning about science, having a scientific occupation, and so on. I did find that the members of most Christian traditions are in propositional belief conflict with science over fact-claims about the world. These fact-claims are few, and do not matter to the everyday lives of the vast majority of Americans.

Having dislodged the systemic knowledge conflict thesis, I engaged in some informed speculation about why propositional belief conflict would exist. First, I considered why mainline Protestants and Catholics would not follow the elites in their tradition and agree with scientists about all claims that scientists make. Second, I speculated about why, if not driven by systemic knowledge constraints, a conservative Protestant would not believe scientists' accounts of human origins. One possible reason is that they could still be Baconians. Another reason is that conservative Protestants defend nonscientific ideas not because they are in conflict with scientists, but because they are in conflict with evangelicals and liberal Protestants over Biblical exegesis. Propositional belief claims that differ from the scientific consensus could also be serving as an identity symbol in creating a collective identity against liberal Protestants and the broader society. A final possible explanation is that conservative Protestants oppose scientific facts not because of how they were generated, but because of their moral implications. I think that what we otherwise know about American society and religion suggests that this is the true conflict with science. I turn to these explanations in the next chapter. 